\title{
EXPLANATION AND JUSTIFICATION: UNDERSTANDING THE FUNCTIONS OF FACT-INSENSITIVE PRINCIPLES
}

\section{KYLE JOHANNSEN}

\author{
Trent University
}

\begin{abstract}
Biographical Note
Kyle Johannsen is an instructor in the Department of Philosophy at Trent University. He is primarily interested in social and political philosophy, especially distributive justice, but he also has interests in applied ethics, especially animal ethics. He has published in AJOB Neuroscience, Dialogue: Canadian Philosophical Review, and Social Philosophy Today
\end{abstract}

\begin{abstract}
In recent work, Andrew T. Forcehimes and Robert B. Talisse correctly note that G.A. Cohen's fact-insensitivity thesis, properly understood, is explanatory. This observation raises an important concern. If fact-insensitive principles are explanatory, then what role can they play in normative deliberations? The purpose of my paper is, in part, to address this question. Following David Miller, I indicate that on a charitable understanding of Cohen's thesis, an explanatory principle explains a justificatory fact by completing an otherwise logically incomplete inference. As a result, the explanatory role such a principle plays is inseparable from its status as a (not necessarily successful) justificatory reason. With this interpretation in hand, I then proceed to argue that Lea Ypi's and Robert Jubb's recent criticisms fail to undermine Cohen's thesis, and that fact-insensitive principles, once discovered, are especially helpful for purposes of deliberation in circumstances characterized by changing and changeable feasibility constraints.
\end{abstract}

\section{Keywords}

G.A. Cohen; fact-insensitive principles; feasibility; socialism; justice

G.A. Cohen's now seminal article 'Facts and Principles' (2003) defends the radical claim that our most fundamental normative principles are justified independently of 
facts. ${ }^{1}$ He maintains that without fundamental, 'fact-insensitive' principles, we cannot make sense of the justificatory relationship between factual reasons and context-specific, action-guiding regulatory principles (Cohen 2008, 265-7). Cohen's thesis, in his own words, is that "a principle can reflect or respond to a fact only because it is also a response to a principle that is not a response to a fact (Cohen 2008, 232)." Understanding what Cohen means by this is a bit tricky, but Andrew T. Forcehimes and Robert B. Talisse have aptly suggested that Cohen's thesis is best understood as an explanatory one (Forcehimes and Talisse 2013, 373-4) . On the assumption that some fact F supports some principle P, explaining why $\mathrm{F}$ supports $\mathrm{P}$ requires invoking a further principle, $\mathrm{P}^{\star}$. To use Cohen's own illustrative example, on the assumption that the fact 'keeping promises is necessary for promisees to pursue their personal projects' supports the principle 'people ought to keep their promises', some further principle is needed to explain the justificatory relationship, e.g., a principle such as 'people should help others pursue their projects' (Cohen 2008, 234-6).

Recognizing that fact-insensitive principles function to explain the facts justifying our moral commitments is essential to understanding the fact-insensitivity thesis. However, it also raises an important concern. If fact-insensitive principles function as explanations, then do they have a role in ethical and political decision making? Understanding why one's factual beliefs supports one's principles, and thus the basis upon which one endorses those principles, is perhaps an important kind of self-knowledge, but is that all it is? If fact-insensitive principles are merely explanatory, then they can have no practical role to play.

The purpose of the present paper is, in part, to address the above mentioned concern. In the next section, I briefly explain Cohen's thesis and the premises he invokes in support of it. Drawing on David Miller (2008), I indicate that on a charitable understanding of the thesis, a fact-insensitive principle explains a justificatory fact by completing an otherwise logically incomplete inference. If the interpretation I advocate is correct, then the explanatory role such a principle plays is inseparable from its status as a (not necessarily successful) justificatory reason.

With Miller's interpretation of the fact-insensitivity thesis in hand, I then proceed to defend Cohen's thesis against two criticisms, one of which challenges it on explanatory grounds and the other on justificatory grounds. The first of these criticisms, authored by Lea Ypi (2012), attempts to convict Cohen of an infinite regress. In reply, I argue that once the logical character of Cohen's thesis is fully appreciated, it is apparent that the

Some of the material comprising this paper was previously presented at Queen's University's Philosophy Colloquium Series. I thank the members of my audience for their comments. I would also like to thank the members of my supervisory committee - Will Kymlicka, Alistair Macleod, and Christine Sypnowich for written comments, as well as two anonymous reviewers for Socialist Studies. Finally, I acknowledge funding from the Social Sciences and Humanities Research Council of Canada.

${ }^{1}$ For a revised version of his 2003 paper, see Cohen 2008, chapter 6. 
assumptions he works with do not commit him to claiming that the force of an explanation always presupposes a further explanation. The second of these criticisms, authored by Robert Jubb (2009), challenges Cohen on the grounds that his thesis pertains to the logical but not the epistemic sense of 'grounding'. An explanatory principle (one that explains why a fact is a justificatory reason for the agent who believes it), though needed to generate a valid argument, does not succeed in epistemically grounding a fact-sensitive principles unless it, i.e., the explanatory principle, and the factual premise or premises it serves alongside, are justified. In reply, I argue that Jubb's critique succeeds in showing that explanatory principles are not sufficient for the justification of fact-sensitive principles, but it does not succeed in undermining their status as necessary conditions for justification. An explanatory principle is required for there to be any sort of inferential relationship between a factual premise and the principle it supports, and thus an explanatory principle is needed to produce a sound argument.

After addressing the above criticisms, I proceed to argue that fact-insensitive principles, once discovered, can be productively extracted from their explanatory setting and employed for purposes of deliberation. Following Pablo Gilabert (2011), I acknowledge that their insensitivity to facts that constitute soft (changeable) feasibility constraints makes them suitable for guiding political transition. What is more, I suggest that our limited epistemic abilities make insensitivity to facts that constitute putatively hard (unchangeable) constraints useful too. Facts we originally took to be permanent sometime change unexpectedly, and when they do, fact-insensitive principles are important for political reform. As we'll see, these observations are of special interest to both socialists and liberal egalitarians.

\section{Fact-Insensitivity and the Third Man}

Put very concisely, Cohen's thesis is that any factual reason to endorse a normative principle presupposes a fact-insensitive normative principle (like Cohen, I shall henceforth use the term 'principle' for short). ${ }^{2}$ Put somewhat less concisely, the view states that for a fact to serve as a reason to endorse a principle, it is necessary that the agent for whom it is a reason be committed to a further, more fundamental principle, the upshot of which is that any fact-supported principle cannot be an agent's most fundamental principle (Cohen 2008, 232-3). To illustrate his thesis, Cohen uses promise-keeping as an example. He notes that the fact 'keeping promises is necessary for promisees to pursue their personal projects' cannot by itself serve as a reason to

\footnotetext{
2 Cohen is careful to define what he means by the terms 'fact' and 'principle'. He stipulates that "a normative principle, here, is a general directive that tells agents what (they ought or ought not) to do, and a fact is, or corresponds to, any truth, other than (if any principles are truths) a principle, of a kind that someone might think reasonably supports a principle (Cohen 2008, 229).”
} 
endorse the principle 'people ought to keep their promises'. In order for it to do so, the agent must believe a further principle that connects said fact to the principle it supports, e.g., a principle such as 'people should help others pursue their projects.' The endorsement of this further principle may or may not itself depend on a fact. If it does, however, then explaining the justificatory force of this fact requires commitment to yet another principle. In any such case, whether it is about promise-keeping, respecting property, etc., one will have to stop one's chain of reasoning at an ultimate principle the endorsement of which does not depend on any fact (Cohen 2008, 234-7).

Cohen indicates that his thesis is grounded in three premises. The first is that whenever a fact serves as a reason to endorse a principle, there is always an explanation for why it does so. The second is that the explanation in question must be some further principle the endorsement of which is independent of the fact it explains. Interestingly, Cohen himself does not provide especially compelling reasons for the reader to believe that these premises are plausible. In support of the first, he offers the supposedly self-evident claim "that there is always an explanation for why any ground grounds what it grounds" (Cohen 2008, 236). With respect to the second, he simply challenges the reader to try and come up with a plausible non-principle explanation for why a particular fact provides a reason to endorse a particular principle. Apparently he is confident that no one will be able to do so. Following David Miller (2008, 33-4), I think it is more effective to say that a further principle is needed in order to establish a valid argument. By way of example, suppose you are committed to the principle 'selfish people should take measures to overcome their selfishness'. Furthermore, suppose that the reason you think this is because of the fact that 'a selfish character makes utility maximization infeasible'. In order for the factual premise 'a selfish character makes utility maximization infeasible' to logically entail the principle 'selfish people should take measures to overcome their selfishness', we need a further principle to serve as a second premise. A good candidate would be 'people should maximize utility'. Explained this way, it is clear why any factual reason requires an explanation. Unless the kind of entailment we are interested in is specifically analytic, no single premise is capable of entailing a conclusion. What is more, the premise we add will need to be a principle, for only a principle that says something about the significance of the fact can generate a set of premises that either deductively or inductively entails the conclusion.

The third and final premise supporting Cohen's thesis states that one's chain of justificatory reasoning actually will stop at an ultimate principle, rather than continuing on indefinitely. Part of the reason Cohen thinks this is so is because he believes it is implausible for the reasons explaining one's endorsement of a principle to be infinite in number. If our minds are finite, then so too are the number of reasons we have for believing a proposition (Cohen 2008, 237). In addition, he also claims that an infinite chain of reasons would violate 'the clarity of mind requirement', according to which his thesis specifically applies to those with a clear grasp of why they endorse the principles 
that they do (Cohen 2008, 233 and 237). This stipulation makes sense if one keeps in mind that Cohen's thesis is about the doxastic explanation of belief. He is interested in the beliefs that explain why an agent believes in a principle (or, in some cases, what she must believe in order to believe that a fact supports a principle she is nonetheless somewhat uncertain of). As such, Cohen is specifically interested in cases of belief where a doxastic explanation is, in fact, available. If an agent can explicitly articulate her reasons for endorsing a principle, then we have an available explanation. Alternatively, she might hold a series of inexplicit reasons that could potentially be brought to light with the help of an interrogator. If, however, she does not hold any reasons at all, or, at the other extreme, somehow holds an infinite regression of reasons, then there is no doxastic explanation available for why she endorses the principle she does.

In a fascinating paper entitled "Facts, Principles and the Third Man" (Ypi 2012), Lea Ypi presents an internal critique of Cohen's three premises. She argues that the fact-insensitivity thesis is vulnerable to a version of the 'third man argument', i.e., an argument put forward in the Platonic dialogue Parmenides which tries to demonstrate that Plato's theory of forms generates an infinite regress. In the present context, an infinite regress of principles is allegedly generated by two of Cohen's claims. The first claim is that there is always an explanation for why a fact grounds what it grounds. Cohen straightforwardly states this as his first premise, so Ypi is certainly right to attribute it to him. The second claim, this time implicit in Cohen's second premise, is that the explanation for a ground must be something other than the ground itself (Ypi 2012, 200-1). A set of claims along these lines is evidently needed for Cohen's argument to take off. It is in light of the first that the justificatory force of a factual reason requires explanation, and it is in light of the second that something more than an appeal to self-evidence is needed. The problem arises when these assumptions are applied to principles and not just facts. If an explanatory principle also requires an explanation, one which is more than just an appeal to self-evidence, then it seems Cohen is stuck with an infinite regress. Any principle that explains a justificatory fact will itself require a further principle to explain it, and that further principle in turn requires yet another principle, etc. There will be no non-arbitrary point at which one can stop the chain of explanatory reasoning (Ypi 2012, 209-13).

One possible reply would be to explicitly restrict the scope of the assumptions Ypi focuses on. Cohen might say that they only apply to facts, though I think he would be hard pressed to say exactly why. A more convincing response is available via an appreciation for the logical character of his thesis. As previously noted, the reason any justificatory fact requires an explanation is because no factual premise can entail a principle by itself. For the factual premise 'keeping promises is necessary for promisees to pursue their personal projects' to entail the principle 'people should keep their promises', we need a further premise such as 'people should help others pursue their projects' to fill the entailment gap. But what is involved in going even further? What 
would constitute an explanation of the explanatory principle itself? One possibility is to offer an explanation for why the agent endorses it. This is equivalent to asking whether the explanatory principle is ultimate, and if it is not, then what further facts and principles explain why the agent takes it to be justified. But none of Cohen's assumptions prevent him from eventually terminating this explanation at an ultimate principle. The claim that there is always an explanation for why a fact grounds what it grounds is not analogous to, and thus does not require Cohen to commit to, the claim that there's always a doxastic explanation for why an agent believes a principle. The former is a matter of what is logically required to complete an entailment. The latter is not.

Suppose, however, that we are interested in something other than explaining endorsement. Suppose we take endorsement of the explanatory principle for granted and instead ask why it explains the relevant fact's justificatory force. If Cohen's assumptions committed him to the position that the force of an explanation always presupposes a further explanation, then he would indeed find himself in infinite regress territory. As we have noted, an explanatory principle explains a factual premise's justificatory force by completing the entailment. Since the fact that 'a selfish character makes utility maximization infeasible' cannot logically entail a commitment to character reform by itself, explaining the agent's commitment to 'selfish people should take measures to overcome their selfishness' requires an additional premise. However, if Cohen's assumptions committed him to the position that explanatory force always requires an explanation, then pointing to the completed entailment would not be enough. It would be necessary to go even further and explain how forming the entailment itself constitutes a successful explanation. For example, to explain why 'people should maximize utility' $\left(\mathrm{P}^{\star}\right)$ explains the justificatory relationship between 'a selfish character makes utility maximization infeasible' (F) and 'selfish people should take measures to overcome their selfishness' (P), we might offer the following hypothetical principle: 'If $\mathrm{P}^{\star}$ and $\mathrm{F}$, then $\mathrm{P}$ '. Of course, the explanatory force of our hypothetical principle would itself have to be explained with a further principle, and the force of this further principle would have to be explained via yet another principle, etc. In other words, if Cohen's assumptions required explaining explanatory force, he would find himself in the same position as Lewis Carroll's Achilles (1895). In his humorous dialogue, Carroll shows that the validity of an entailment must sometimes be taken for granted. To do otherwise would invite an infinite regress, for each time we try to prove the validity of an entailment by adding another premise, we in turn create a new entailment that must be proven valid, and thus an endless chain ensues. To avoid this regress, certain logical forms, e.g., inference rules such as Modus Ponens or Modus Tollens, must be accepted as basic, and the arguments that satisfy those forms must not require any further premises in order to be valid. Thankfully, though, Cohen's assumptions do not commit him to claiming that the validity of an entailment always requires a further premise. What 
Cohen's thesis requires is explicating the implicit premise or premises in an otherwise patently invalid justification. Adding the premise needed to turn a patently invalid justification into a valid one is not the same thing as rejecting the basic status of inference rules.

The last kind of explanation we might offer for an explanatory principle is one that explains why it functions as a ground. This question becomes intelligible once we have noted that explanatory principles serve as premises in arguments. Unlike the other senses of explaining an explanatory principle, Cohen's assumptions actually do commit

him to requiring such an explanation. As is hopefully clear by now, though, explaining why a principle functions as a ground does not require an infinite regress. If we want to know why a principle is a reason to endorse another principle, then we just need to figure out which explanatory premise or premises would form a valid argument. Thus were we to be asked why the agent's commitment to helping others pursue their projects entails her endorsement of a promise-keeping requirement, it would not be amiss to mention what we already know, namely that the agent believes the factual premise 'keeping promises is necessary for promisees to pursue their personal projects'. Just as the non-factual premise can be invoked to explain the factual premise's force, so too can the factual premise be invoked to explain the non-factual premise.

In summary, I've argued that 'the third man argument', though perhaps applicable to Plato's theory of forms, is not an effective criticism of Cohen's fact-insensitivity thesis. Of the three likely interpretations of what it means to explain an explanatory principle, not one forces Cohen into an infinite regress.

\section{The Practical Significance of Fact-Insensitive Principles}

In the previous section, I sought to explain Cohen's fact-insensitivity thesis and to defend it against an alleged infinite regress. In this section, I attempt, among other things, to shed light on the role of fact-insensitive principles in practical deliberation. Addressing this matter is important because the nature of the fact-insensitivity thesis encourages doubts about the practical significance of fact-insensitive principles. As we have noted, the principles the thesis establishes are explanatory. They serve to explain why agents endorse the fact-sensitive principles they do. In what sense are explanatory principles useful for deliberation, though? Understanding why we endorse the fact-sensitive principles we do is surely a good thing, but how does that understanding bear on the selection of fact-sensitive principles we are not yet certain about?

The first thing to note is that fact-insensitive principles are not just explanatory. This point comes to light by appreciating, once more, that they are premises in arguments. Though it is true that a fact-insensitive principle functions to explain why one or more factual claims have the justificatory significance they do, they do so 
specifically by completing the justification said fact or facts are premises in. Of course, logically complete justifications are not always successful justifications. As Robert Jubb notes, explanatory principles are needed to 'logically ground' fact-sensitive principles, but in cases where an explanatory principle is unjustified (or where the factual premise it serves alongside is unjustified), said principle does not suffice to 'epistemically ground' the fact-sensitive principle whose endorsement it explains, i.e., it does not suffice to give us good reason to accept that the fact-sensitive principle is true. By way of example, Jubb points out that the principle "everyone who is evil should be killed", in combination with the factual premise "all people under six feet tall are evil", would explain the agent's endorsement of a fact-sensitive principle which states "everyone under six feet tall should be killed (Jubb 2009, 344)." However, it's clear that the principle "everyone who is evil should be killed", though explanatory, does not justify the (independently implausible) fact-sensitive principle "everyone under six feet tall should be killed", as neither the explanatory principle nor the factual co-premise it serves alongside are acceptable. The upshot, Jubb notes, is that a chain of reasoning that eventually terminates in a fact-insensitive principle explains the agent's endorsement of, but does not necessarily justify, the fact-sensitive principle with which one began (Jubb 2009, 344-5).

Jubb's point is well taken, but the extent to which the distinction between premises that logically ground a conclusion (justify it on the condition that they're true) and premises that epistemically ground a conclusion (actually justify it) threatens the justificatory significance of fact-insensitive principles depends on whether explanatory principles are necessary for logical grounding of any sort, or whether they are merely necessary for deductive validity. If explanatory principles are merely needed for deductive validity, then Jubb's point demonstrates not only the insufficiency of fact-insensitive principles for justification, but their lack of necessity as well. Since arguments can be sound without being deductively valid, fact-insensitive principles would not be needed for soundness, i.e., one might have factual premises that inductively support fact-sensitive principles, and no further explanatory principle(s) would be needed to account for this. However, if explanatory principles are needed to generate an inferential relationship of any sort, then fact-insensitive principles are at least necessary for justification. After all, an argument's soundness is comprised of (a) the acceptability of its premises and (b) the inferential relationship between its premises and its conclusion, so soundness requires, at the very least, that an argument's premises inductively support its conclusion, i.e., that the hypothetical truth of the premises make the truth of the conclusion reasonably likely. As it becomes apparent upon reflection, however, a factual premise cannot even inductively support a principle without a non-factual co-premise to back it up. For example, consider once more the principle that 'selfish people should take measures to overcome their selfishness'. This time, though, let us say that the factual premise offered in support of it is the fact that 'a selfish 
character is one of the factors that can potentially impede utility promotion'. Without a non-factual co-premise, the above fact provides no inferential support of any kind for the above principle. To invoke it in argument would be a complete non-sequitur. Some further principle is needed to produce an inference, and though one which supplies deductive logical grounding would do, e.g., one that states 'people should remove all factors that can potentially impede utility promotion', so too would one that supplies inductive grounding. For instance, the principle 'people should promote utility' suffices to tell us why the agent has reason to remove potential barriers to utility promotion, but it does not generate a deductively valid argument. The possibility that selfishness does not impede utility in some contexts, or that there may be other, more significant barriers that should be removed instead, demonstrates that the hypothetical truth of the premises 'a selfish character is one of the factors that can potentially impede utility promotion' and 'people should promote utility' supports but fails to guarantee the conclusion 'selfish people should take measures to overcome their selfishness'.

Once the justificatory indispensability of fact-insensitive principles is appreciated, it is clear that nothing prevents exporting a plausible fact-insensitive premise to non-explanatory contexts, i.e., contexts where the project is to select new fact-sensitive principles, rather than to explain the appeal of those already endorsed. For instance, the principle 'people should help others pursue their projects', though initially of interest because it explains the justificatory force of the fact that 'keeping promises is necessary for promisees to pursue their personal projects', would presumably make a contribution to one's moral deliberations after its discovery. Someone committed to this principle might, upon reflection, find that it supports revising the norms she currently lives by, e.g., supports giving more to charity, voting for left wing political parties instead of right wing ones, etc. The extent of her discovery's revisionary significance will depend on the weight she assigns it and the degree to which it conflicts with the other commitments governing her norms, but it could and should make some difference to how she lives her life.

In recent work, Pablo Gilabert explores considerations related to political transition that shed further light on the practical significance of fact-insensitive principles (2011). He points out that an appreciation for the malleability of some feasibility constraints requires that we take a 'transitional standpoint' with respect to the implementation of a fact-insensitive ideal. One of his insights for Cohen's work is that implementing a fundamental principle is not simply a matter of adopting action-guiding principles that reflect feasibility constraints and the requirements of other fundamental principles. It also requires paying attention to the ways in which our actions can affect our social and political context, and thus the ways in which they can affect the feasibility of realizing more desirable arrangements in the future (Gilabert 2011, 59-63). The other insight is that principles the content of which is not beholden to facts comprising soft feasibility constraints, i.e., malleable constraints such as culture, prevailing political views, 
etc., have an important practical role to play. Were we to amend the content of our most fundamental principles in order to ensure that what they prescribe does not exceed the bounds of what is feasible within our present context, then we would have no standard in light of which to identify which of our factual circumstances pose a barrier to realizing states of affairs even more desirable than those presently accessible. Our principles would be beholden to, rather than critical of, the facts that constrain what is immediately possible to accomplish, and thus would be unable to serve as a standard in light of which to conduct a gradual process of transition.

Cohen expresses thoughts similar to Gilabert's in his earlier writing on analytic Marxism. When reflecting upon the failure of the Soviet Union and its depressing implications for the future of socialism, Cohen argues that socialists should not conclude that capitalism, because apparently more feasible, is therefore more desirable. To do so would be akin to forming adaptive preferences, and though adaptive preferences are psychologically useful insofar as they help us cope with our limited capacities, they can also make us lose sight of what's valuable (Cohen 1995, pp. 253-5). On Cohen's view, a successful socialist society would embody a number of fundamental values much better than a capitalist society does; values such as justice and community (Cohen 1995, pp. 259-64; Cohen 2009, pp. 12-45). And though a successful socialist society is not presently within reach, we should be careful not to forget why it was worth striving for one in the first place. As Cohen puts it, "If you cannot bear to remember the goodness of the goal that you sought and which is not now attainable, you may fail to pursue it should it come within reach, and you will not try to bring it within reach (Cohen 1995, p. 256)." Which facts pose a barrier to bringing about socialism is a debatable matter, but it seems clear that capitalist market relations cultivate social attitudes that aren't conducive to socialist reforms. In so far as implementing socialism requires a strong sense of communal care between citizens, the transition will be difficult if citizens have been socialized into adopting an individualistic mentality focused on the acquisition of personal wealth. Implementing socialism thus arguably requires a change in social attitude, one that could perhaps be accomplished through moral education.

Gilabert's analysis shows how principles insensitive to soft feasibility constraints are useful, but it does not show how principles that are also insensitive to hard feasibility constraints are useful. What practical role might principles insensitive to even permanent features of the human condition play? Though I do not pretend to have a comprehensive answer to this question, at least some of the importance of fact-insensitive principles is derivable from our epistemic limitations. We are not always able to determine which constraints are hard and which are soft. Technological and other advancements sometimes overturn the facts constituting a putatively hard constraint. In situations where a set of factual constraints are lifted, it may be the case that previously optimal fact-sensitive principles cease to be so. To be cognizant of this, however, requires an understanding of what one found appealing about those principles, an 
understanding that survives factual change and enables one to perceive that the formerly optimal principles now fall short.

Consider the implications of emerging genetic technology. This sort of technology, once it has reached a sufficiently advanced state, will predictably have the power to enhance human physical and mental abilities far beyond the present norm. This possibility raises questions of justice, among other things. ${ }^{3}$ In the contemporary distributive justice literature, egalitarian theorists have generally considered it to be a hard fact that governments cannot influence the distribution of natural abilities. Nevertheless, they recognize that justice requires addressing natural inequalities. Some theorists, such as Cohen, think that unequal natural ability is an intrinsic source of unfairness (Cohen 1989, 917-8). ${ }^{4}$ Others, such as Ronald Dworkin and Kok-Chor Tan, think it is only unfair insofar as it is permitted to affect individuals' access to social goods (Dworkin 2000, 79-90; Tan 2008, 671-3 and 679-80). Whether one thinks unequal natural abilities are intrinsically or merely extrinsically unfair matters little for political practice if only social goods fall within the scope of government influence. If natural abilities can be affected, however, then a seemingly arcane dispute over the precise nature of their unfairness suddenly carries much more practical significance. For one who thinks natural inequality is intrinsically unfair, improvements in genetic technology would be a reason to adopt principles that target more than just the distribution of social goods. In so far as certain ability-boosting genetic interventions are morally acceptable, considerations of fairness may suffice to ground a principle that gives priority to boosting the abilities of the disadvantaged. Noticing this, however, requires clarity about why one supports addressing natural inequalities via the redistribution of social goods in the first place. If it is merely because one thinks the effect of natural inequality on the distribution of social goods should be either mitigated or eliminated, then the emergence of new genetic technology is seemingly unimportant. If, however, it is because one thinks natural inequality is unfair in part due to its social effects but also in and of itself, then the facts associated with technological advancement become normatively significant. Only when we are clear about the content of the principles that explain our fact-sensitive commitments can we react appropriately to factual change.

In conclusion, I hope to have demonstrated that understanding the explanatory character of Cohen's thesis in terms of what is logically required for either an inductively or deductively valid inference empowers said thesis to avoid a number of difficulties, namely infinite regress and practical impotence. Though Cohen's thesis may still be vulnerable to other difficulties not mentioned here, it is my hope that a proper

\footnotetext{
${ }^{3}$ For a stimulating book discussing various issues surrounding justice and genetic modification, see Buchanan et al., 2000.

${ }^{4}$ In addition to holding it himself, Cohen attributes this view (perhaps improperly) to Rawls. See Cohen 2008, 96-7.
} 
understanding of it will help commentators hone in on the real issues, whatever those may be. ${ }^{5}$

\section{References Cited}

Buchanan, Allen., Dan W. Brock, Norman Daniels and Daniel Wikler. 2000. From Chance to Choice: Genetics \& Justice. New York: Cambridge University Press.

Carroll, Lewis. 1895. "What the Tortoise Said to Achilles". Mind 4, no. 14: 278-80.

Cohen, G.A. 1989. "On the Currency of Egalitarian Justice”. Ethics 99, no. 4: 906-44.

Cohen, G.A. 1995. "The Future of a Disillusion". In Self Ownership, Freedom, and Equality, eds. G.A. Cohen, Jon Elster, and John Roemer. Cambridge: Cambridge University Press. Pp. 245-65.

Cohen, G.A. 2003. "Facts and Principles". Philosophy \& Public Affairs 31, no. 3: 211-45.

Cohen, G.A. 2008. Rescuing Justice and Equality. Cambridge, MA: Harvard University Press.

Cohen, G.A. 2009. Why Not Socialism? Princeton: Princeton University Press.

Dworkin, Ronald. 2000. "Equality of Resources". In Sovereign Virtue: The Theory and Practice of Equality, by Ronald Dworkin. Cambridge, MA: Harvard University Press. Pp. 65-119.

Forcehimes, Andrew T. and Robert B. Talisse. 2013. "Clarifying Cohen: A Response to Jubb and Hall". Res Publica 19, no. 4: 371-9.

\footnotetext{
5 According to Forcehimes and Talisse, the issue worth addressing is whether Cohen's thesis, if true of moral beliefs, must also be true of the correct set of moral principles, assuming there is a correct set. This may indeed be a matter worthy of exploration. See Forcehimes and Talisse 2013, 379 . For other allegedly serious issues, see David Miller 2008; Thomas Pogge 2008; Daniel Kofman 2012; and Kai Nielsen 2012.
} 
Gilabert, Pablo. 2011. "Debate: Feasibility and Socialism". The Journal of Political Philosophy 19, no. 1: 52-63.

Jubb, Robert. 2009. "Logical and Epistemic Foundationalism about Grounding: the Triviality of Facts and Principles". Res Publica 15, no. 4: 337-53.

Kofman, Daniel. 2012. "How Insensitive: Principles, Facts and Normative Grounds in Cohen's Critique of Rawls”. Socialist Studies 8, no. 1: 246-66.

Miller, David. 2008. "Political Philosophy for Earthlings". In Political Theory: Methods and Approaches, eds. David Leopold and Marc Stears. Oxford: Oxford University Press. Pp. 29-48.

Nielsen, Kai. 2012. "Rescuing Political Theory from Fact-Insensitivity". Socialist Studies 8, no. 1:216-45.

Pogge, Thomas. 2008. “Cohen to the Rescue!” Ratio 21, no. 4: 454-75.

Tan, Kok-Chor. 2008. "A Defense of Luck Egalitarianism". The Journal of Philosophy 105, no. 11: 665-90.

Ypi, Lea. 2012. "Facts, Principles and the Third Man". Socialist Studies 8, no. 1: 196-215. 